\title{
Special issue: The art of Latina and Latino elderhood
}

\author{
Katynka Z. Martínez ${ }^{1}$ Mérida M. Rúa ${ }^{2}$
}

Accepted: 28 September 2021 / Published online: 24 November 2021

(c) The Author(s), under exclusive licence to Springer Nature Limited 2021

This special issue presents distinct and overlapping approaches to Latinx/a/o aging studies, bringing together scholars from the humanities and arts, social sciences, and health sciences. ${ }^{1}$ The existing research on aging is focused almost exclusively on white older adults. When the gerontological literature has noted the significant differences in the life trajectories and present livelihoods of white and minoritized older populations, there has been less appreciation of the latter's internal heterogeneity. The growing research and advocacy on behalf of older adults seldom regard the needs and concerns of aging Latinas and Latinos, while Latinx/a/o studies scholarship and advocacy have seldom attended to older adults' circumstances and needs. One of our goals is to draw attention to and encourage further scholarship on older adult Latinas, Latinos, and Latinxs. Another intention is for this modest project to invite more conversations between critical gerontology and Latinx/a/o studies.

We are not the first to propose such a conversation. In 1987, sociologists Steven P. Wallace and Elisa Linda Facio published "Moving beyond Familism" in the Journal of Aging Studies. They urged scholars interested in the status and care of "Chicano/ Latino elderly" to think outside of the narrow cultural bounds of family and respect. Following a critical orientation away from prevailing biomedical and social work concerns to life-course approaches, political economy, and feminist theory, among other frameworks, Wallace and Facio suggested some possible benefits of gerontological theory to the study of "Chicano/Latino aging." For instance, a life-course perspective would engage aging as a sociohistorical process sensitive to differences among and between groups categorized under the "Chicano/Latino" rubric, as well as identify continuities over the range of a life that could nuance past, present, and

\footnotetext{
1 In parts of this introduction, we use the terminology of the 1980s and 1990s, such as "Chicano/Latino" and "Latina and Latino," as used by scholars whose work we build from and the older adult populations themselves. Our use of Latinx/a/o studies and Latinx reflects the current engagement with gender, cis heteronormative ideologies, and future directions of the field.
}

Mérida M. Rúa

mrua@northwestern.edu

Katynka Z. Martínez

katynka@sfsu.edu

1 San Francisco State University, San Francisco, CA, USA

2 Northwestern University, Evanston, IL, USA 
future understandings of "Chicano/Latino elderly." However, Wallace and Facio said little of how Latina and Latino studies scholars were already cautioning against approaches to Latinidades that singularize historical experiences and obscure critical distinctions within and among groups. More recently, social science, health science, and policy scholars interested in Latina and Latino older adults have organized through and published studies as part of the Aging in the Americas Conference. Headed by Jacqueline L. Angel, Kyriakos Markides, Fernando M. Torres-Gil, and William A. Vega, the conference series has supported and advanced multidisciplinary projects covering health and health-care policy, changing demographics, and the structural and behavioral aspects of Latina and Latino aging since 2001.

The existing research on Latina and Latino aging leans heavily toward studies of social and structural inequalities within the demographic, sociological, public policy, and applied social services literatures (Delgado 1998, 2015; Vega et al. 2015). Demographers and public policy scholars call attention to the rise of the aging into older adulthood populations and the ethnoracial heterogeneity that will distinguish old age in the years to come. They emphasize that these demographic shifts will have far-reaching social and economic implications, some determinedly adverse in the realms of health and retirement if left unaddressed, such as the negative consequence of Latinas' and Latinos' lifelong earnings and savings disadvantages (Gassoumis et al. 2015; Angel 2018; also see Villa and Aranda 2000; Sáenz et al. 2013; Sáenz 2015). Social networks and support and housing and care work are at the core of the sociological and social work scholarship concerned with Latina and Latino longevity. The family's role in the care of aging parents has been a defining feature of the scholarship on Latinas and Latinos, evidenced in Facio and Wallace's proposal to move beyond familismo (Wallace and Facio 1987; Facio 1996; Ramos 2007; Guzzardo and Sheehan 2013; Angel et al. 2017). As a constructed cultural norm, familismo describes the venerated status of elders in Latinx families. Assumptions at the core of familismo are that family members hold great respect for elders, take personal responsibility for aging parents' care, and culturally censure institutionalized care.

As much as intergenerational households that adhere to principles of familismo exist, it is also true that Latinx family care arrangements are dynamic and evolving, demonstrating more complexity than can be explained by assimilation. ${ }^{2}$ The reality is that older adults' ability to co-reside with family has become increasingly challenging. Economic and housing inequalities limit adequate, affordable housing options, resulting in fewer multigenerational households and the dispersion of families across city limits and county and states lines. The changes in living arrangements could indicate that adult children may be less available or unwilling to provide care for aging parents. At the same time, scholars point to the modified forms of family caregiving that continue to occur even when older adult parents live independently or in assisted living facilities or nursing homes (Facio 1996; Ramos 2007; Guzzardo and Sheehan 2013). Notwithstanding the fact that some older adults may

\footnotetext{
2 Sociologist Lorena Garcia (2020) similarly observes an overreliance on assimilation theories in her study of Latinx parents and language use in families.
} 
prefer living on their own to co-residing, environmental pressures likely factor in to this decision (Facio 1996; Freidenberg 2000; Ramos 2007). ${ }^{3}$

Too often, though, within this important scholarship, older adult Latinas' and Latinos' voices, perspectives, and experiences of growing old-in other words, their stories that reveal their multifaceted dimensions-are ancillary to the figures, patterns, emerging themes, or interventions, or off the page altogether. For example, the literature on familismo usually emphasizes the health and well-being effects on adult children, notably daughters, of caring for older parents while raising their children (Sánchez-Ayéndez 1998). Inadvertently, efforts to shed light on the invisible labor of female family members by and large veil the experiences and viewpoints of care recipients. ${ }^{4}$ Contrary to popular belief, most older people do not require assistance with extensive personal care; they may even continue to be principal caregivers themselves, members of the paid labor force, or engaged contributors in their communities (de Medeiros 2017; also see Rodríguez-Galán 2013; Wallace 1992). ${ }^{5}$

To our knowledge, we can count on one hand the number of single-author monographs devoted to Latina and Latino older adults' outlooks and existences of growing old, how they define, make meaning of, and navigate their daily lives and circumstances. Two notable studies are the late sociologist Elisa Facio's Understanding Older Chicanas (1996) and anthropologist Judith Freidenberg's Growing Old in El Barrio (2000).

Drawing on participant observation and oral histories, Facio addressed earlier studies' default misconception of Chicano aging as a homogeneous process, taking into account that women outlive and outnumber men and remain widowed or live alone more often than their male agemates. Her groundbreaking work engaged how older Chicanas defined and viewed their old age, particularly how they questioned, revised, and sometimes challenged gender dynamics and expectations regarding their roles in the family as nurturers, childcare providers, or recipients of care, and their sexual subjectivities. In other words, Facio illuminated how older Chicanas interpreted and made meaning of their lives beyond wifehood, motherhood, or grandmotherhood.

\footnotetext{
3 Of all older Latino groups, Puerto Ricans are most likely to live alone; since the 1980s, there has been a steady decrease in the percentage of older adult Puerto Ricans co-residing with an adult child. See De Vos and Arias 2003, pp. 91-101.

Some older adults have stated a preference for formal care to avoid becoming a burden to their families, especially their children; others see it as maintaining their independence and control over care arrangements (Guzzardo and Sheehan 2013).

4 For an exception, see Guzzardo et al.'s Boston-based study of the social support experiences of older Puerto Ricans with disabilities (2017).

5 According to the 2018 Profile on Older Americans, $4 \%$ of noninstitutionalized older adults between the ages 65 and 74 and $9 \%$ between the ages of 75 and 84 needed help with personal care. Those 85 and older, $20 \%$ in 2017, are more likely to require help with daily activities such as bathing, toileting, dressing, eating, and other activities because of reduced mobility and agility. In 2017, 23\% of people 65 and over were members of racial and ethnic minority populations, and of those, $8 \%$ identified as persons of Hispanic origin (Administration on Aging 2018).

Of course, this doesn't mean that the varied care needs among the heterogeneous constituencies that make up the older adult population are addressed. Nonetheless, there should be more nuance and consideration of all older persons' agency and capabilities in discussions of "population aging" and care.
} 
Freidenberg's foundational policy ethnography (2000) examines the social strategies and social networks Puerto Rican elders in NYC's El Barrio cultivate to deal with anxieties and crises, both actual and hypothetical, as they age in place. The available scholarship on older adult Latinas and Latinos living in low-income and impoverished urban neighborhoods associates their use of public space and resources with their notions of safety. Freidenberg contends that respect and understanding of older adults' health, economic, social, and spatial needs and desires (along with those of their families, if applicable) must inform policy intended to address their long-term care.

Scholars from various social science disciplines are embarking on research projects ranging from the social, biomedical, demographic, cultural, health/mental health, and retirement security concerns of Latina/o/x communities as they experience greater longevity. New directions in the study of Latinx older adulthoods are unfolding in the interdisciplines. A growing corpus of political-economy-informed performance studies and ethnic studies scholarship contemplate racialized Latinx aging bodies vis-à-vis the performance of queer gestures, expressions of gender and sexuality, and knowledge production (see Rodriguez 2014, 2015; Rivera-Servera 2017; Hernández 2018). We look forward to more research that centers and deeply engages LGBTQIA + Latinx elderhood and older adults' ongoing connection and participation with cultural production, as well as studies of their community activism and social life more generally. This volume gives value and impetus to enhancing studies in these emerging sites of inquiry.

Building from the valuable biomedical, quantitative, qualitative, and policydriven foundation, and inspired by the evolving interdisciplinary scholarship, this special issue integrates humanistic approaches to center Latina and Latino lived experiences of growing older. This special issue provides a varied and multidimensional portrait of Latina and Latino elderhood by situating the health sciences and policy approaches alongside humanistic social science and artistic modes of expression and analysis.

"The Art of Latina and Latino Elderhood" examines the everyday lives and expressive cultural practices of a population often revered but not meaningfully engaged as thinking, feeling, and changing subjects within Latinx/a/o studies. In different ways and through distinct mediums, contributors take on the social realities and meanings of corporeal changes and notions of decline that are part and parcel of growing old without indulging in binaries that circulate downcast or successful ageist views of later life. The special issue is structured around approaches that reflect the multiple registers of presentation and analyses used in the field of Latina/o/x studies. Therefore, contributions include not only traditional article formats but also fiction, diálogo, photography, and monologue, some mediums that have previously not been included in the pages of Latino Studies. We combine essay and artistic formats into related sections. By including these diverse formats, this special issue stays true to the multidisciplinary and interdisciplinary orientations and paradigms used in Latinx/a/o studies to investigate the histories and political, economic, and social forces that shape Latinidades.

This approach further recognizes that literary offerings such as fiction and memoir have contributed to the knowledge base related to Latina and Latino 
aging. The creative works of Helena María Viramontes (1985), Amina Gautier (2014) and Kali Fajardo-Anstine (2019) engage the physicality of an aging body by delving deeper than simply addressing mobility limitations. Their short stories illustrate that while Latina and Latino elders may not be physically active, they create mental maps of their neighborhood informed by having witnessed multiple urban renewal projects. And while circular migration may no longer be an option for an older Latina, she can still confer meaning to her current landscape by making sense of it in relation to what she has left behind. These creative writers take a more innovative approach than much behavioral and health science research by moving away from a simple celebration of familismo as an innate commitment to family and instead recognizing the toll that caregiving places on grandparents when a child's parent is absent. The fact that Viramontes, Gautier, and FajardoAnstine address these themes without falling into a trap of sentimentality is testament to artistic modes of analysis being especially well-suited to offering meditations on the experience of growing old.

The purposeful inclusion of "art" in the title of this special issue invokes the ways we see art as something both created and inhabited. We recognize that there is an art to how people live their lives. By titling this special issue "The Art of Latina and Latino Elderhood," we foreground the innovative and creative skill sets and techniques older Latinas and Latinos develop and practice as they continuously define, improvise, and challenge tired, unimaginative notions of oldness that circulate within and beyond their social worlds.

"The Art of Latina and Latino Elderhood" opens by pairing a reflective analysis on the field of gerontology with speculative fiction.

The essay by Fernando M. Torres-Gil, a leading scholar on demographics, aging, and public policy, frames many of the themes and topics covered in this special issue and argues that gerontology must face new realities as Latinos become the nation's largest ethnic group. He considers the policy challenges and opportunities that arise with recognizing the great variation among aging Latina and Latino baby boomers and reflects on how these changing values and experiences redefine notions of elderhood. Torres-Gil ends by asking us, as scholars in all stages of our careers and life cycles, to move beyond notions of perpetual youth and longevity-denial to consider more imaginative ways of inhabiting roles as the new elders instead.

Taking up this challenge, writer and Latinx/a/o studies scholar Nelly Rosario contributes an excerpt, "Operation Granma G," from her novel-in-progress, How the Medicines Go Down. This speculative story, set on an elite medical tourist resort located off the coasts of Mexico and Cuba, centers on a revolutionary doctor who runs a clandestine clinic for low-level workers denied medical care on the island. "Operation Granma G" portrays how the doctor's New York City-based "rebel senior-citizen" mother, Gertrudis, supports his cause. Manipulating the biomedicalization of elderhood, Gertrudis strategically performs aches and pains for doctors, pharmacists, social service agencies, and insurance companies to remit needed medical prescriptions and supplies to the clinic. 
Through the lens of popular culture and art, the next section engages issues of older adult health, well-being, and agency from the fields of exercise psychology and visual studies.

Health sciences scholars David X. Marquez, Susan Aguiñaga, Priscilla G. Vasquez, Isabela G. Marques, Guilherme M. Balbim, and Michelle Jaldin examine the development and health benefits of a physical activity program designed for older Latinas and Latinos. Marquez and colleagues describe and assess older Latina and Latino perspectives on the role of dancing in their lives. In this context, participants discuss their involvement in creating the BAILAMOS dance program, which includes merengue, cha-cha-cha, bachata, and salsa. Focus group participants convey how the dance program builds community, increases physical activity, and improves cognition.

Communication and cultural studies scholar Katynka Z. Martínez and Chicana visual artist Yolanda Lopez contribute the photo essay, "Hairpiece," chronicling Lopez's experiences with medical professionals, hormone replacement therapy, and her decision to no longer pluck her chin hairs. Lopez reflects on her 1978 Guadalupe triptych, which offered portraits of herself, her mother, and her grandmother. While Yolanda manipulated the image of the Virgen de Guadalupe to reimagine the Catholic icon, she now manipulates her own face to interrogate the expectation of women aging "gracefully."

Centered on the varied experiences of older Latinas, the next section employs the modes of diálogo and theater, film, and ethnographic analysis to further the much-needed discussion on the gendered politics of aging in popular representations and their meanings in daily life.

Justina Machado, star of the reimagined One Day at a Time, facilitates a diálogo on aging, gender, and race on the stage and screen with actors Ivonne Coll, Olga Merediz, and Alma Martinez. Coll and Merediz have had numerous roles in off-Broadway and Broadway productions as well as film and television. Recently retired, Coll received critical acclaim for her role as Elba on Jane the Virgin. Merediz reprises her Tony-nominated role of Abuela Claudia in the movie adaptation of In The Heights. Introduced to audiences through the 1979 production of Zoot Suit, Martinez has continued working in theater and film while receiving a $\mathrm{PhD}$ in drama. All three actors have seen a resurgence in casting offers late into their careers. They reflect with Machado on the ebbs and flows of roles for young, middle-aged, and older Latinas.

"The Abuela Perplex: Unscripting Latina Elderhood," by Mérida M. Rúa, professor of Latina/o/x studies and American studies, presents a textual reading and ethnographic view of Latina elderhood. The essay deconstructs popular renderings of the abuela figure in film, television, and the stage, and through an examination of the daily lives and relationships of older Latinas in a gentrifying Chicago neighborhood.

The final section examines themes of structure and agency and transnational connections and social relations in the respective daily lives of Salvadoran and Puerto Rican older adults. Through philosophical social theory and monologue, the pieces disrupt notions of elderhood as a static stage in the life cycle disengaged from society. 
Latin American and Latina/o/x studies scholar Jorge E. Cuéllar's essay contemplates elderhood as an analytic to examine the fragmented sociality of contemporary El Salvador, as well as anticipating its importance to the country's political and economic futures as the general population uptrends toward later adulthood. Focusing on the struggle for old age dignity in the national debate around pensions and the experiences of retiree repatriates from the United States, Cuéllar highlights the local and transnational movements of older adults and their integral role in the ever-evolving production of Salvadoran transnational community and national well-being.

Puerto Rican artist Antonio Martorell's monologue, "Veveviejo: A Lesson Learned, The Beginning and End of Life," poetically and performatively sounds out the significance of age in society, highlighting the experiences of Puerto Ricans on the island and in the diaspora. He offers a critical and creative approach to the assorted vulnerabilities of the very old and the very young, primarily as rooted in their lack of economic, political, and physical capital.

The contributions in this special issue demonstrate how age can be featured as a primary analytic without sacrificing attention to other categories of social difference, sociopolitical contexts, and institutions of power. The variety of methodological and theoretical perspectives featured here center the experiences of an understudied community among Latinxs. Doing so enriches Latinx/a/o studies discussion and scholarship by offering a more holistic approach that reveals new dimensions to our understandings of elderhood and, by extension, Latinxs of all ages. We recognize that these intergenerational and cross-genre intellectual conversations are often cultivated in community-engaged spaces and academic conferences but rarely reemerge in journal publications. We hope that this special issue inspires scholars of Latinx/a/o studies to think in more expansive and integrative ways about age, aging, and later life that continues a conversation across and between the arts and humanities, the sciences, and the social sciences.

Acknowledgements The authors thank Fernando M. Torres-Gil and the Latino Studies editorial board for their comments and suggestions on earlier drafts of the introduction.

\section{References}

Administration on Aging. 2018. 2018 profile of older Americans. Washington, DC: US Department of Health and Human Services.

Angel, J.L. 2018. Aging policy in a majority-minority nation. Public Policy and Aging Report 28 (1): 19-23.

Angel, J.L., S. Rote, and K. Markides. 2017. The role of the Latino family in late-life caregiving. In Later-life social support and service provision in diverse and vulnerable populations: Understanding networks of care, ed. J.M. Wilmoth and M. Silverstein, 38-53. Oxfordshire, UK: Taylor and Francis.

Delgado, M., ed. 1998. Latino elders and the twenty-first century: Issues and challenges for culturally competent research and practice. New York: Haworth Press.

Delgado, M. 2015. Baby boomers of color: Implications for social work policy and practice. New York: Columbia University Press.

de Medeiros, K. 2017. Rethinking family and family structures. In The short guide to aging and gerontology, 97-122. Bristol, UK: Policy Press. 
De Vos, S., and E. Arias. 2003. A note on the living arrangements of elders 1970-2000, with special emphasis on Hispanic subgroup differentials. Population Research and Policy Review 22 (1): $91-101$

Facio, E. 1996. Understanding older Chicanas: Sociological and policy perspectives. Thousand Oaks, CA: Sage.

Fajardo-Anstine, K. 2019. Galapago. In Sabrina \& corina, 105-118. New York: One World.

Freidenberg, J.N. 2000. Growing old in El Barrio. New York: New York University Press.

Garcia, L. 2020. Language and (re)negotiations of Latinx identity: Latinx parents' approaches to Spanish and Bilingualism. Social Problems 67 (1): 40-55.

Gassoumis, Z. D., K. H. Wilber, and F. M. Torres-Gil. 2015. The economic security of Latino baby boomers: Implications for future retirees and for healthcare funding in the U.S. In Challenges of Latino Aging in the Americas, ed. W. A. Vega, K. S. Markides, J. L. Angel, and F. M. Torres-Gil, 355-378. Switzerland: Springer.

Gautier, A. 2014. Bodega. In Now we will be happy, 28-37. Lincoln: University of Nebraska Press.

Guzzardo, M. T., W. E. Adams, I. L. G. Todorova, and L. M. Falcón. 2017. Harmonizing beliefs with realities: Social support among older Puerto Ricans with disabilities. Special Collection-Ethnogerontology 7 (2): 1-13.

Guzzardo, M., and N.W. Sheehan. 2013. Puerto Rican Elders' knowledge and use of communitybased long-term care services. Journal of Gerontological Social Work 56 (1): 26-48.

Hernández, J. 2018. Beauty marks: The Latinx surfaces of loving, becoming, and mourning. Women and Performance: A Journal of Feminist Theory 28 (1): 67-84.

Ramos, B.M. 2007. Housing disparities, caregiving, and their impact for older Puerto Ricans. Journal of Gerontological Social Work 49 (1/2): 47-64.

Rivera-Servera, R. 2017. History in drag: Latina/o queer affective circuits in Chicago. In The Latina/o Midwest reader, ed. O. Valerio-Jiménez, S. Vaquera-Vásquez, and C.F. Fox, 187-196. Urbana: University of Illinois Press.

Rodriguez, J.M. 2014. Sexual futures, queer gestures, and other Latina longings. New York: New York University Press.

Rodriguez, J.M. 2015. Pornographic encounters and interpretative interventions: Vanessa del Rio: Fifty years of slightly slutty behavior. Women and Performance: A Journal of Feminist Theory 25 (3): 315-335.

Rodríguez-Galán, M.B. 2013. Grandmothering in life-course perspectives: A study of Puerto Rican grandmothers raising grandchildren in the United States. In Transitions and transformations: Cultural perspectives on aging and the life course, ed. Caitrin Lynch and Jason Denely, 137-150. New York: Berghahn Books.

Sáenz, R. 2015. The demography of the elderly in the Americas: The case of the United States and Mexico. In Challenges of Latino aging in the Americas, ed. W.A. Vega, K.S. Markides, J.L. Angel, and F.M. Torres-Gil, 197-223. Switzerland: Springer.

Sáenz, R., A. Fox, and S. J. García. 2013. Latino elderly in Nonmetropolitan America. In Rural aging in 21st Century America: Understanding population trends and processes, ed. Nina Glasgow and E. Helen Berry, 115-140. Dordrecht: Springer.

Sánchez-Ayéndez, M. 1998. Middle-aged Puerto Rican women as primary caregivers to the elderly. In Latino elders and the twenty-first century: Issues and challenges for culturally competent research and practice, ed. M. Delgado, 75-97. New York: Haworth Press.

Vega, W.A., K.S. Markides, J.L. Angel, and F.M. Torres-Gil, eds. 2015. Challenges of Latino aging in the Americas. Switzerland: Springer.

Villa, V.M., and M.P. Aranda. 2000. The demographic, economic, and health profile of older Latinos: Implications for health and long-term care policy and the Latino Family. Journal of Health and Human Services Administration 23 (2): 161-180.

Viramontes, H. M. 1985. Neighbors. In The moths and other stories, 109-125. Houston, TX: Arte Público Press.

Wallace, S.P. 1992. Community formation as an activity of daily living: The case of Nicaraguan immigrant elderly. Journal of Aging Studies 6 (4): 365-383.

Wallace, S.P., and E.L. Facio. 1987. Moving beyond Familism: Potential contributions of gerontological theory to studies of Chicano/Latino aging. Journal of Aging Studies 10 (1): 337-354. 
Publisher's Note Springer Nature remains neutral with regard to jurisdictional claims in published maps and institutional affiliations.

Katynka Z. Martínez is professor in the Latina/Latino Studies Department at San Francisco State University. Her most recent publications include "Latina/Latino Community Journalism: A San Francisco Case Study" in The Routledge Companion to Latina/o Media (2017) and "'I Exist Because You Exist:' Teaching History and Supporting Engagement through Bilingual Community Journalism" in Civic Engagement in Diverse Latinx Communities: Learning from Social Justice Partnerships in Action (2018). Martínez's research areas include community journalism, visual culture, and community-generated artwork related to día de los muertos.

Mérida M. Rúa is professor in the Latina and Latino Studies Program at Northwestern University. She is author of A Grounded Identidad: Making New Lives in Chicago's Puerto Rican Neighborhoods (2012), editor of Latino Urban Ethnography and the Work of Elena Padilla (2010), and co-editor of Critical Dialogues in Latinx Studies: A Reader (2021). Her current research examines issues and themes at the intersections of aging, urban life, and Latina, Latino and Latinx studies, with an emphasis on older Puerto Ricans in Chicago. 